\title{
Adaptive direct slicing of a commercial CAD model for use in rapid prototyping
}

\author{
S. H. Sun • H. W. Chiang $・$ M. I. Lee
}

Published online: 21 December 2006

(C) Springer-Verlag London Limited 2006

The online version of the original article can be found at http://dx.doi. org/10.1007/s00170-006-0651-y.

S. H. Sun $(\bowtie)$

Department of Mechanical Engineering, Kun Shan University,

Tainan Hsien, Taiwan, Republic of China

e-mail: sh-sun@mail.ksut.edu.tw

H. W. Chiang $\cdot$ M. I. Lee

Department of Mechanical Engineering,

Chang Gung University,

Taoyuan, Taiwan, Republic of China

The originally published reference list of this article unfortunately contained a mistake. Incorrect reference:

6. Chua CK, Jacob GK, Tong M (1997) Interface between CAD and rapid prototyping systems. Part 1: A study of existing interfaces. Int J Adv Manuf Technol 13(8):566-570 Correct reference:

6. Chua CK, Gan JGK, Tong M (1997) Interface between $\mathrm{CAD}$ and rapid prototyping systems. Part 1: A study of existing interfaces. Int J Adv Manuf Technol 13(8):566-570 